early discharge, and long-stay hospital patients is recorded; it has shown that mothers confined in hospital begin to feed their babies and become established breast-feeders more of ten than do women delivered at home.

We wish to thank Dr. A. P. Roberts for permission to review cases in his care ; Miss G. Clayton, Matron of St. Luke's Maternity Hospital, and Miss E. R. Entwhistle, Supervisor of Midwives, for their invaluable help on numerous occasions; and Dr. G. Hill for statistical advice. We wish to pay tribute to a very loyal junior staff.

\section{REFERENCES}

Brit. med. 7., 1964, 2, 70.

College of General Practitioners, Bradford Group (1966). Lancet, 1, 536.

Craig, G. A., and Muirhead, J. M. B. (1967). Brit. med. 7., 3, 520.

Douglas, J., Edgar, W., and Horne, K. (1961). Med. Offr, 106, 333.

Hellman, L. M., Kohl, S. G., and Palmer, J. (1962). Lancet, 1, 227.

Ministry of Health (1958). Report of the Maternity Services Committee (Cranbrook Report). H.M.S.O., London.

Pinker, G. D., and Fraser, A. C. (1964). Brit. med. 7., 2, 99.

Theobald, G. W. (1959). Ibid., 2, 1364.

- (1962). Lancet, 1, 735.

\title{
Obstetric Aspects of the Early Discharge of Maternity Patients
}

\author{
G. A. CRAIG, ${ }^{*}$ M.B.E., F.R.C.S., F.R.C.o.G. ; J. M. B. MUIRHEAD, ${ }^{*}$ M.B., B.CH., M.R.C.o.G.
}

\section{Brit. med. F., 1967, 3, 520-522}

It is now nine years since planned early discharge of the normal mother and normal baby on the second day of the puerperium was commenced in Bradford. The scheme has since been in continuous operation, and to date approximately 13,000 puerperal women have been managed in this way. Theobald $(1959,1962)$ and Douglas et al. (1961) described the reasons for and the initial planning of the scheme, and recorded its early results. In 1966 members of the College of General Practitioners (Bradford group) reported on a survey of 100 early discharge cases.

Five thousand consecutive case records have been analysed in order to show the types of patients that have participated in the scheme. Abnormalities that occurred but which were not thought sufficiently important to warrant retaining the patient in hospital for longer than 60 hours have been recorded. The purpose of the paper is to present these results, and it also includes a discussion of our experience.

\section{Patients Discharged Early}

Of the 5,000 patients whose records were analysed $70 \%$ were booked for hospital confinement and 30\% were emergency admissions either during the antenatal period or during labour. The age distribution is recorded in Table $I$. The number of

TABle I.-Age Distribution of Patients Discharged Early

\begin{tabular}{|c|c|c|c|c|}
\hline \multicolumn{3}{|c|}{ Age Group } & Primigravidae & Multigravidae \\
\hline $\begin{array}{l}\text { Under } 20 \text { years } \\
20-24 \text { years } \\
25-29 \text { years } \\
30-34 \text { years } \\
35 \text { years and over }\end{array}$ & $\begin{array}{ll}. & \cdots \\
. & \cdots \\
\cdots & \cdots \\
. & \cdots\end{array}$ & $\begin{array}{l}\cdots \\
\cdots \\
\cdots \\
\cdots\end{array}$ & $\begin{array}{l}421(8 \cdot 4 \%) \\
644(12 \cdot 9 \%) \\
320(6 \cdot 4 \%) \\
136(2 \cdot 7 \%) \\
30(0.6 \%)\end{array}$ & $\begin{array}{r}89(1.8 \%) \\
695(13.9 \%) \\
1,028(20.6 \%) \\
848(17.0 \%) \\
789(15.8 \%)\end{array}$ \\
\hline
\end{tabular}

TABle II.-Parity Distribution of Patients Discharged Early

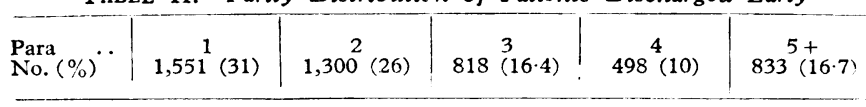

\begin{tabular}{|c|c|c|c|c|c|c|}
\hline \multirow{2}{*}{ Duration of Stay } & \multicolumn{2}{|c|}{ Primiparae } & \multicolumn{2}{|c|}{ Multiparae } & \multicolumn{2}{|c|}{ Total } \\
\hline & No. & $\%$ & No. & $\%$ & No. & $\%$ \\
\hline $\begin{array}{l}\text { Patients discharged in } \\
\text { less than } 24 \text { hours }\end{array}$ & 56 & $1 \cdot 1$ & 127 & 2.5 & 183 & 3.7 \\
\hline $\begin{array}{l}\text { Patients discharged in } \\
24-36 \text { hours. } \\
\text { P. }\end{array}$ & 1,094 & 21.9 & 2,450 & $49 \cdot 0$ & 3,544 & $70 \cdot 9$ \\
\hline $\begin{array}{c}\text { Patients discharged in } \\
36-60 \text { hours.. }\end{array}$ & 401 & $8 \cdot 0$ & 872 & $17 \cdot 4$ & 1,273 & $25 \cdot 4$ \\
\hline
\end{tabular}

women in each parity group is shown in Table II. The length of stay in hospital of the 5,000 patients is given in Table III.

The original policy was to discharge on the second day those mothers and babies whose condition did not seem to justify further hospital care. A number of women who had had abnormalities during labour or at the time of delivery have participated in the scheme. The incidence of intrapartum complications in the 5,000 patients whose records were analysed is shown in Table IV. The complications that occurred at the time of delivery in patients discharged early are recorded in Table V.

TABLE IV.-Intrapartum Complications in Patients Discharged Early

\begin{tabular}{c|c|c}
\hline Intrapartum Complication & Primigravidae & Multigravidae \\
\hline Artificial rupture of membranes $\ldots$ & $512(10 \cdot 2 \%)$ & $916(18 \cdot 3 \%)$ \\
$\begin{array}{l}\text { Oxytocin drip } \\
\text { Pyrexia } 99-99 \cdot 8^{\circ} \mathrm{F} .\left(37 \cdot 2-37 \cdot 7^{\circ} \mathrm{C} .\right)\end{array}$ & $84(1 \cdot 7 \%)$ & $197(3.9 \%)$ \\
on two or more occasions & $17(0.3 \%)$ & $38(0.8 \%)$ \\
Pyrexia $100^{\circ} \mathrm{F} .\left(37 \cdot 8^{\circ} \mathrm{C}.\right)$ and over & $3(0.06 \%)$ & $9(0 \cdot 2 \%)$ \\
\hline
\end{tabular}

TABle V.-Complications at Time of Delivery in Early Discharge

\begin{tabular}{|c|c|c|}
\hline Complication & Primigravidae & Multigrav:dae \\
\hline 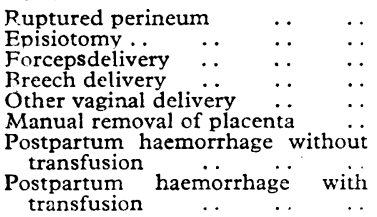 & $\begin{array}{l}520(10 \cdot 4 \%) \\
533(10.7 \%) \\
185(3.7 \%) \\
27(0.5 \%) \\
16(0.3 \%) \\
9(0.2 \%) \\
49(1.0 \%) \\
2(0.04 \%)\end{array}$ & $\begin{array}{c}866(17.3 \%) \\
324(6.5 \%) \\
79(1.6 \%) \\
69(1.4 \%) \\
31(0.6 \%) \\
30(0.6 \%)\end{array}$ \\
\hline
\end{tabular}

\section{Hospital Organization}

The early discharge scheme has resulted in a considerable increase in the work done in the hospital. St. Luke's Maternity Hospital is the only maternity hospital in Bradford. It was designed to manage approximately 1,500 confinements a year. Before the introduction of the scheme in 1958 this figure had risen to 2,000 a year and since then it has continued to rise until in 1964 it almost reached 4,000. Such an increase imposes a very severe strain on all members of the hospital staff, particularly those engaged in the labour ward. In such circumstances it is difficult to maintain standards and the continuous

* Consultant Obstetrician and Gynaecologist, Bradford. 
supervision that is necessary. It was therefore necessary to review the existing arrangements within the hospital and to effect any changes that would help a willing and competent nursing staff, whose numbers were inadequate, to meet the increased demands made upon them.

Ward clerks and ward and theatre orderlies have been appointed as liberally as our financial resources permit in order that the nursing staff may be relieved, so far as is possible, from all non-nursing duties. The labour ward of 12 beds is at the time of writing staffed with six sisters, six midwives, five pupil midwives, two ward clerks, four theatre orderlies, and five ward orderlies. Staff rotation between the various wards is practised. The theatre is now in charge of a sister who is not a midwife. This particular innovation has been a success. So far as is possible, all operative procedures and abnormal deliveries are performed in the operating-theatre.

Patients in labour are admitted direct to the labour suite, which is situated on the ground floor of the hospital. This suite has accommodation for 12 patients in labour, has two delivery rooms, an anaesthetic room, and an operating-theatre. Continuous with the labour suite is a recovery ward of 12 beds. Patients who are thought to be suitable for early discharge are accommodated in the recovery ward until the decision to discharge or not to discharge them is made.

If for any reason a patient and her baby are not discharged early they are immediately transferred to one of the lying-in wards. Those mothers who are to remain in hospital for 10 days are usually transferred from the labour ward to one of the lying-in wards shortly after their delivery has been completed. If, however, it is thought that their condition after delivery warrants continued close supervision then they are accommodated in the recovery ward until their condition has improved sufficiently to warrant their transfer to a lying-in ward. As a result of this reorganization the acute work of the hospital is accommodated on one floor and there has been a considerable reduction in the movement of patients within the hospital. It has also facilitated both medical and nursing arrangements.

We have been greatly impressed with the advantages that have resulted from a centralized labour ward, with adjacent delivery room, operating-theatre, and recovery room. We believe that single rooms should be provided for women in labour and that these should be large enough to allow normal deliveries to be conducted in them. Such an arrangement would reduce the movement of patients within the hospital and make it much easier for those who wish to have their husbands with them during labour.

It is undoubtedly better if patients who are expected to be discharged early are not accommodated alongside those who have to remain for 10 days.

\section{Results}

Mortality.-There have been no maternal deaths.

Readmission.-The incidence of readmission has been compared with the admissions to hospital of patients confined in their own homes (see Fig. 1). The most common indications for readmission were persistent bleeding from the uterus and delayed involution. A few patients were readmitted with pyrexia. Those who were readmitted were not dangerously ill and responded rapidly to appropriate treatment.

Eclampsia.-The number of cases of eclampsia that have occurred in patients booked for confinement in St. Luke's Maternity Hospital during the years 1948-65 inclusive is shown in Fig. 2. Since the inception of the early discharge scheme the number of patients booked for confinement in the hospital has risen by nearly $50 \%$, and the admissions of patients with hypertension, proteinuria, and oedema have increased. The majority of the latter are counted as booked patients unless delivery occurred shortly after admission. Despite this, the incidence of eclampsia in booked patients has not gone up and has remained consistently below that of non-booked patients.

Table III shows that it has not been possible to discharge all patients on the morning of the second day ; in nearly all cases the decision to discharge a patient in less than 24 hours was taken because beds were urgently required. Patients whose

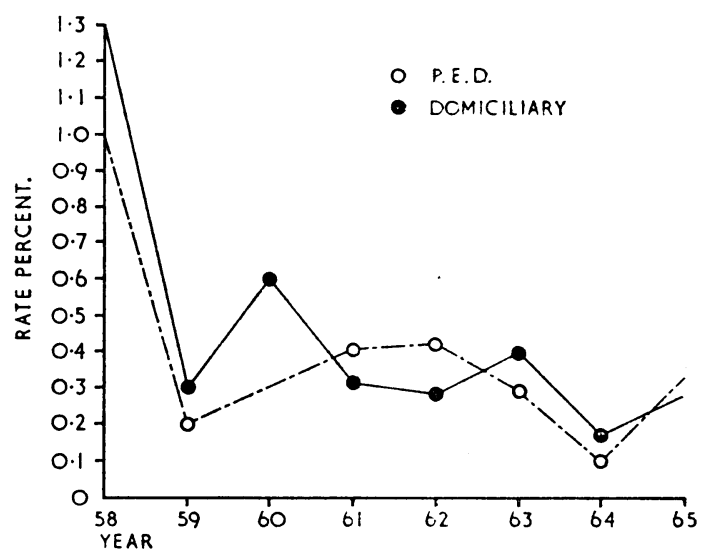

FIG. 1.-Readmission rates, domiciliary and planned early discharge patients.

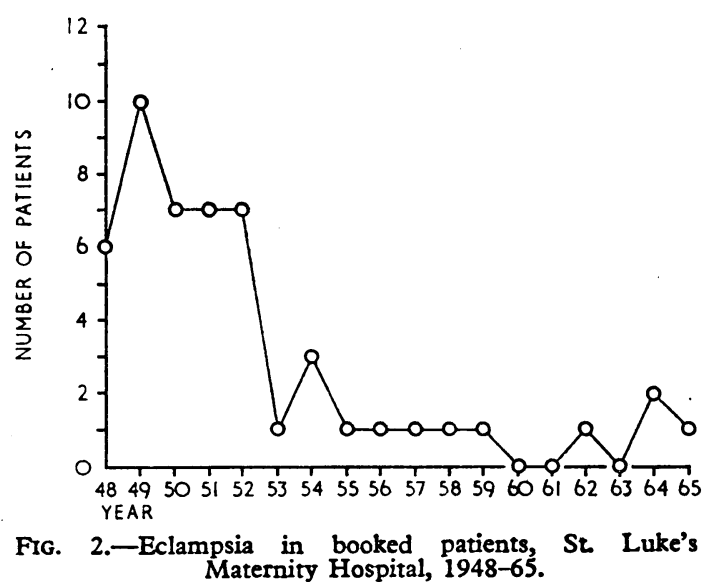

discharge was delayed until the morning of the third day included those whom it had not been possible to get home by midday on the second day and some about whom our information on their home conditions was incomplete or in need of verification.

\section{Discussion}

The Bradford scheme has had a mixed reception from those engaged in obstetrics. Some are opposed to it (Claye, 1964 ; Corbett, 1964 ; Annual Report of the Health of Kingston-uponHull, 1964). Others have accepted it with reluctance, without conviction, and as an emergency measure whereby inadequate obstetric services could be enabled to meet the demands of the population explosion, until such times as adequate hospital, nursing, and medical facilities became available (Ministry of Health, 1958 ; Report of the Maternity Services Emergency Informal Committee 1963 ; B.M.F., 1964). A third group appears to have accepted the scheme as being a safe and practical way of managing the normal mother and normal baby once the hazards of confinement are over (Douglas et al., 1961 ; Hellman et al., 1962 ; Rhodes, 1964 ; Pinker and Fraser, 1964).

The early discharge of patients who have had abnormalities is probably the most reasonable basis of criticism, but our results have shown that early discharge can take place without apparent detriment to the patient or her baby, even though certain 
abnormalities have occurred during the process of labour and delivery.

St. Luke's Maternity Hospital continues to make frequent use of artificial rupture of the membranes not only as a method of induction but also to help labour to become established. The oxytocin drip is used when necessary. It is not thought that the need to use either or both of these procedures precludes early discharge if the condition of the mother and baby is satisfactory after delivery.

Pyrexial patients were not discharged if the pyrexia persisted after delivery. The wisdom of discharging patients who have been pyrexial during labour may be questioned, but there has been no reason to regret the decision taken in the 67 patients included in this inquiry. Our policy has been to repair all ruptured perineums with catgut, in order to avoid the necessity for suture removal at home. This policy has worked well, and wound healing has been satisfactory. If the forceps or the ventouse has been used to deliver the head from the pelvic outlet early discharge takes place if the baby's condition is satisfactory. This is not considered wise if operative delivery has been effected from the mid-cavity of the pelvis. Many babies in the latter group do not show signs of abnormality on the second day. The great majority of these could be discharged early with safety, but a few could not, and the paediatrician obviously requires more time before he can feel confident that intracranial injury has not occurred. For the same reasons the early discharge of all babies delivered by the breech has now been discontinued.

The analysis showed that 36 of the 5,000 patients had some form of cardiac disability. They were all "stage I cardiacs," who had been well throughout their pregnancy and labour and on the first two days of the puerperium. Their discharge was necessary in order to release beds for incoming patients, and, though none of them is known to have suffered any ill effect as a result of early discharge, it is not recommended that cardiac patients should participate in the scheme.

Readmission rates are a good index of morbidity among patients discharged early. The provision of suitable accommodation for mothers with their babies when readmission is necessary is obviously desirable irrespective of whether early discharge is practised or not. It is unfortunate that St. Luke's Maternity Hospital has not yet got suitable accommodation to permit this to be done. An attempt to compare the medical state of a group of early discharge mothers with that of a group of mothers confined at home has not been pursued, as very soon it was apparent that valid conclusions could not be reached because of the many variable factors encountered.

It is desirable that the patient should be home by midday, as this allows ample time for the domiciliary midwife to assure herself that the mother and baby are satisfactorily settled. Patients are transferred as sitting patients, two per ambulance. They are accompanied by a part-time midwife employed by the local health authority. A few patients go home by private transport.

Doubts have been expressed that the Bradford scheme would interfere with the training and attitude of midwives. In our experience this has not been so. The local health authority has been able to maintain a full quota of domiciliary midwives, and on occasion has a waiting-list of women who wish to join the service. The hospital has never found it necessary to close beds because of staff shortages, and, while it is true that the staffing position is never fully satisfactory, difficulties were being experienced long before the introduction of planned early discharge. The existing administrative arrangements for the maternity services make it difficult to achieve the close and continuous co-operation between the three branches of the service that is necessary to ensure the continuity of medical and nursing care which is essential if planned early discharge is to be successful. If it is accepted that early discharge is a safe procedure then future policy should take into account the wishes of the patient regarding her place of confinement, provided that her medical and obstetric state is satisfactory.

An inquiry was made during 1964-5 of 225 women who had had normal confinements in hospital. Of these, 161 remained in hospital for less than 72 hours, and 64 of them for 10 days. They were asked to state where they would have preferred to have their baby: $50 \%$ of the 10-day group and $43.5 \%$ of the 2-day group were satisfied with their place of confinement (S.E. (Diff.) $=7.4 \%$ - that is, a difference that is not significant). No marked difference in preference was noted in the different age groups and there was no statistically significant difference expressed by women in different social classes. An earlier inquiry of the 161 women who had been confined in hospital and discharged in less than 72 hours showed that $44 \%$ of them were satisfied with the arrangements.

Early discharge has many attractions for the high-risk multigravidae, who are not infrequently reluctant to be admitted to hospital.

Our experience has shown that it is not necessary for $40-50 \%$ of puerperal patients to occupy a hospital bed for 10 days if their homes are suitable and adequate, and medical and nursing care can be provided for them. It has been alleged that early discharge of the puerperal patient from hospital means that she will return to her full range of domestic duties immediately. There is no reason why she should do so to any greater extent than those women who have been confined at home, and it may even be that the earlier ambulation and performance of light household duties are beneficial. There is no reason why the quality of postnatal care provided by the family doctor and the domiciliary care should be inferior to that provided in hospital.

\section{Summary and Conclusions}

The case records of 5,000 consecutive patients who were discharged from hospital within 60 hours of delivery have been analysed. Our experience has been that planned early discharge does not result in increased maternal morbidity nor does it add to the maternal risk. Modifications in the internal arrangements and staffing of the hospital have been described.

The scheme has proved to be an efficient and economic way of ensuring that the maximum number of mothers and babies receive the benefit of hospital care at the time of their greatest need for it.

An appreciable number of patients like and request early discharge. It is to be hoped that this will be recognized by the various authorities and that a more flexible approach to the management of the first 10 days of the puerperium will become the accepted rule.

We are indebted to the Leeds Regional Hospital Board for a grant to enable the analysis of the patients' records to be carried out. Thanks are due to our colleague, Mr. A. C. Muir, who kindly gave permission for the records of patients under his care to be included in the analysis. In addition, we have received valuable help from Mr. Haley, the Secretary, from Miss Clayton, Matron of St. Luke's Maternity Hospital and her staff, and from Mr. H. A. H. Melville. We also wish to express our appreciation for the help given by the Health Department of the City of Bradford.

\section{REFERENCES}

Annual Report of the Health of Kingston-upon-Hull, 1964.

Brit. med. $7 ., 1964,2,70$.

Claye, A. (1964). Brit. med. 7., 2, 1007.

Claye, A. (1964). Brit. med. Y., 2, 1007. Corbett, H. V. (1964). Brit. med. f., 2, 1263

Corbett, H. V. (1964), Brit. med. F., 2, 1263.

Douglas, J., Edgar, W., and Horne, K. (1961). Med. Offr, 106, 333.

Hellman, L. M., Kohl, S. G., and Palmer, J. (1962). Lancet, 1, 227.

Ministry of Health (1958). Maternity Services Committee (Cranbrook Report). H.M.S.O., London.

Pinker, G. D., and Fraser, A. C. (1964). Brit. med. 9., 2, 99.

Report of the Maternity Sevices Emergency Informal Committee 1963 London.

Rhodes, P. (1964). Lancet, 2, 746.

Theobald, G. W. (1959). Brit. med. f., 2, 1364.

Theobald, G. W. (1959). Brit. Lancet, 1, 735 